\title{
TH2H-6
}

\section{Fully Printed Tunable Phase Shifter for L/S-Band Phased Array Application}

Mohammad Nikfalazar ${ }^{1}$, Christian Kohler ${ }^{2}$, Andreas Friederich ${ }^{2}$, Mohsen Sazegar ${ }^{1}$, Yuliang Zheng ${ }^{1}$, Alex Wiens ${ }^{1}$, Joachim R. Binder ${ }^{2}$ and Rolf Jakoby ${ }^{1}$

${ }^{1}$ Technische Universität Darmstadt, Germany ${ }^{2}$ Institute for Applied Materials (IAM-WPT), Germany 


\section{Outline}

- Motivation

- $\quad$ Development of Low Temperature Sintered BST Thick-films

- MIM Varactor Fabrication and Measurement

- $\quad$ Phase Shifter Design and Simulation

- $\quad$ Phase Shifter Fabrication And Measurement

- Conclusion

- Outlook 


\section{Motivation}

- Multi frequency functionality:

$>$ Tunable phase shifters

$>$ Tunable antennas

$>$ Tunable filters

- A tunable component can reduce

$>$ Size

$>$ Complexity

$>$ power consumption

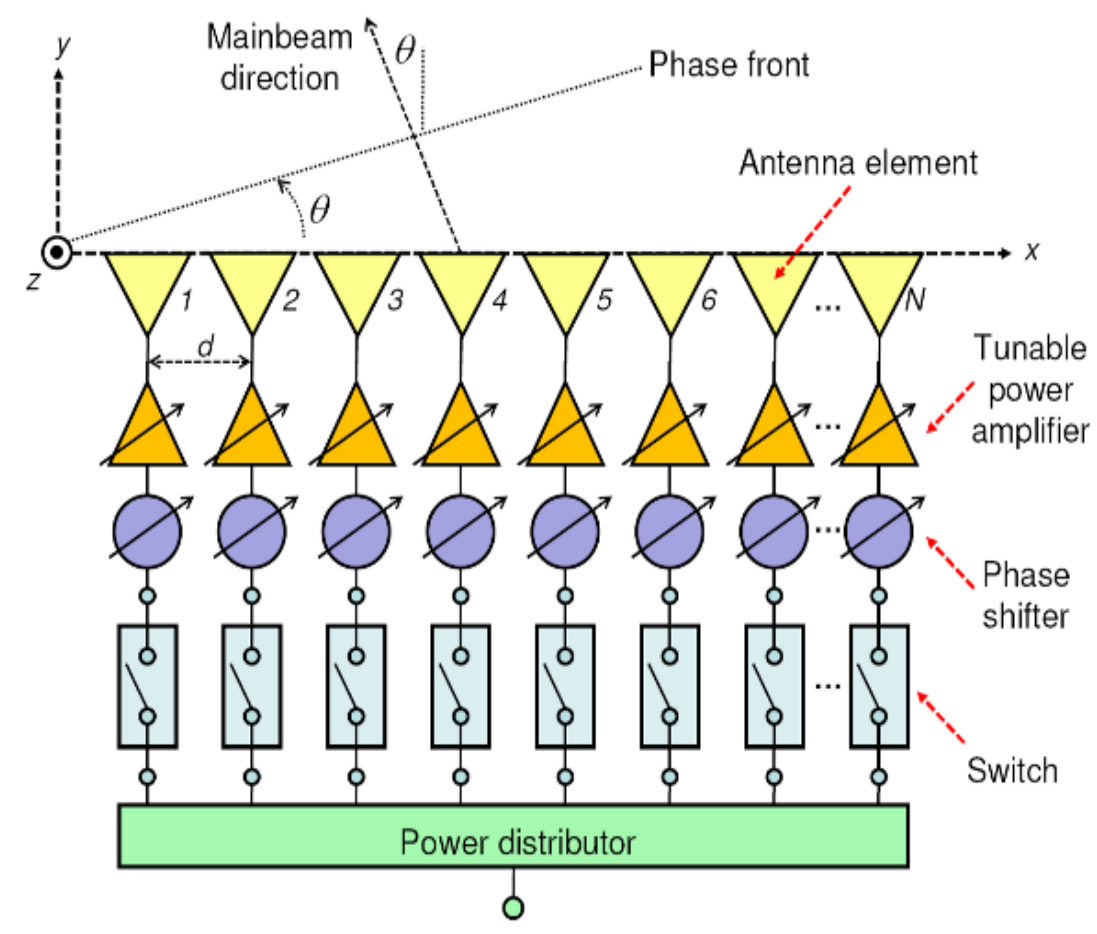

- The functional components in a tunable circuit are tunable varactors 


\section{Motivation}

\section{Why BST Thick-Film?}

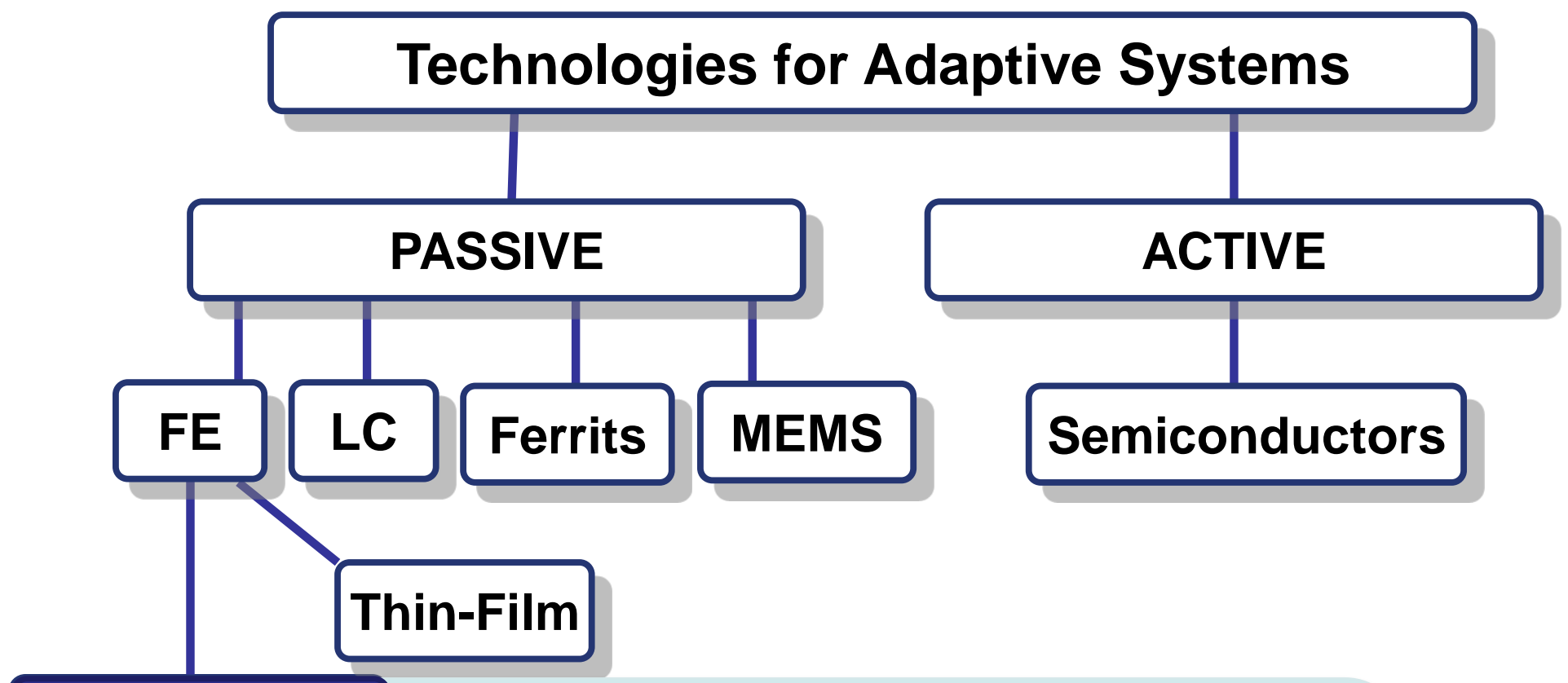

\section{Thick-Film}

$\oplus$ Screen printing - low cost $\quad \oplus$ High tuning speed

$\oplus$ Ceramic based - solid state $\oplus$ High linearity

$\oplus$ Simple Integration \& packaging $₫$ Low power consumption 


\section{Motivation}

- Tunable Dielectric : Barium-Strontium-Titanate (BST)

$>$ Permittivity changes by applying an electrostatic field

$>$ Basic tunable component

- Tunable Interdigital Capacitor (IDC)
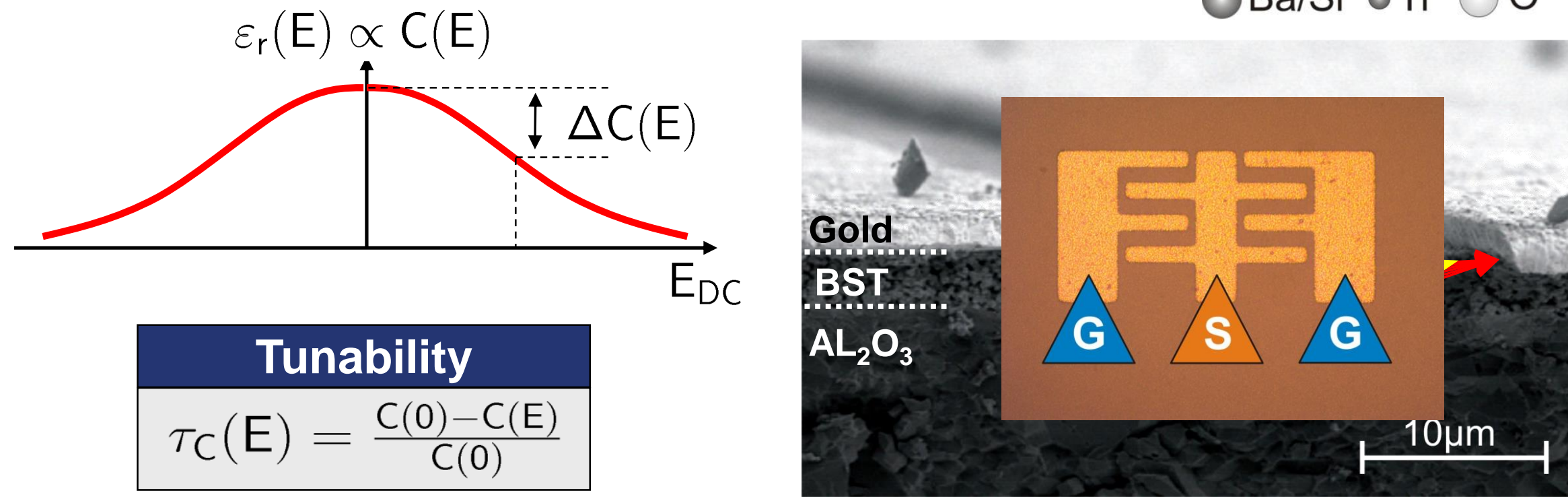

Tunability

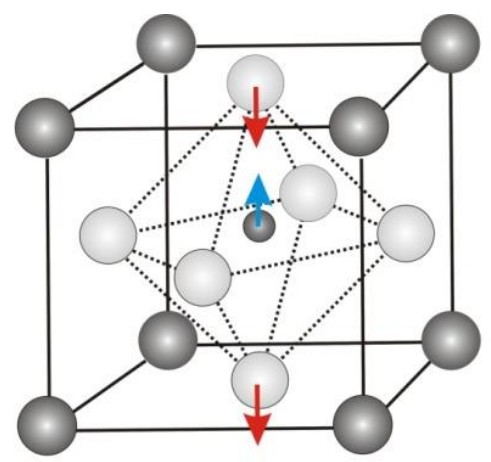

$\bigcirc \mathrm{Ba} / \mathrm{Sr} \odot \mathrm{Ti} \bigcirc \mathrm{O}$

\begin{tabular}{|c|}
\hline Tunability \\
$\tau_{\mathrm{C}}(\mathrm{E})=\frac{\mathrm{C}(0)-\mathrm{C}(\mathrm{E})}{\mathrm{C}(0)}$ \\
\hline
\end{tabular}




\section{Motivation}

\section{- IDC Limitations:}

$>$ Minimum gap is restricted $\longrightarrow$ Reduce maximum electric field per $\mu \mathrm{m}$

$>$ Delicate fabrication process

$>$ Low FoM

$>$ Geometry efficiency

\begin{tabular}{|c|}
\hline $\begin{array}{c}\text { Material Tunability } \\
\tau_{\varepsilon}(\mathrm{E})=\frac{\Delta \varepsilon_{\mathrm{r}}(\mathrm{E})}{\varepsilon_{\mathrm{r}}(0)}\end{array}$ \\
\hline $\begin{array}{c}\text { Component Tunability } \\
\tau_{\mathrm{C}}\left(\mathrm{E}_{\text {eff }}\right)=\frac{\Delta \mathrm{C}\left(\mathrm{E}_{\text {eff }}\right)}{\mathrm{C}(0)}\end{array}$ \\
\hline Geometry Efficiency \\
\hline$\chi_{\text {geo }}\left(\mathrm{E}_{\text {eff }}\right)=\frac{\tau_{\mathrm{C}}\left(\mathrm{E}_{\text {eff }}\right)}{\tau_{\varepsilon}\left(\mathrm{E}_{\text {eff }}\right)}$ \\
\hline
\end{tabular}

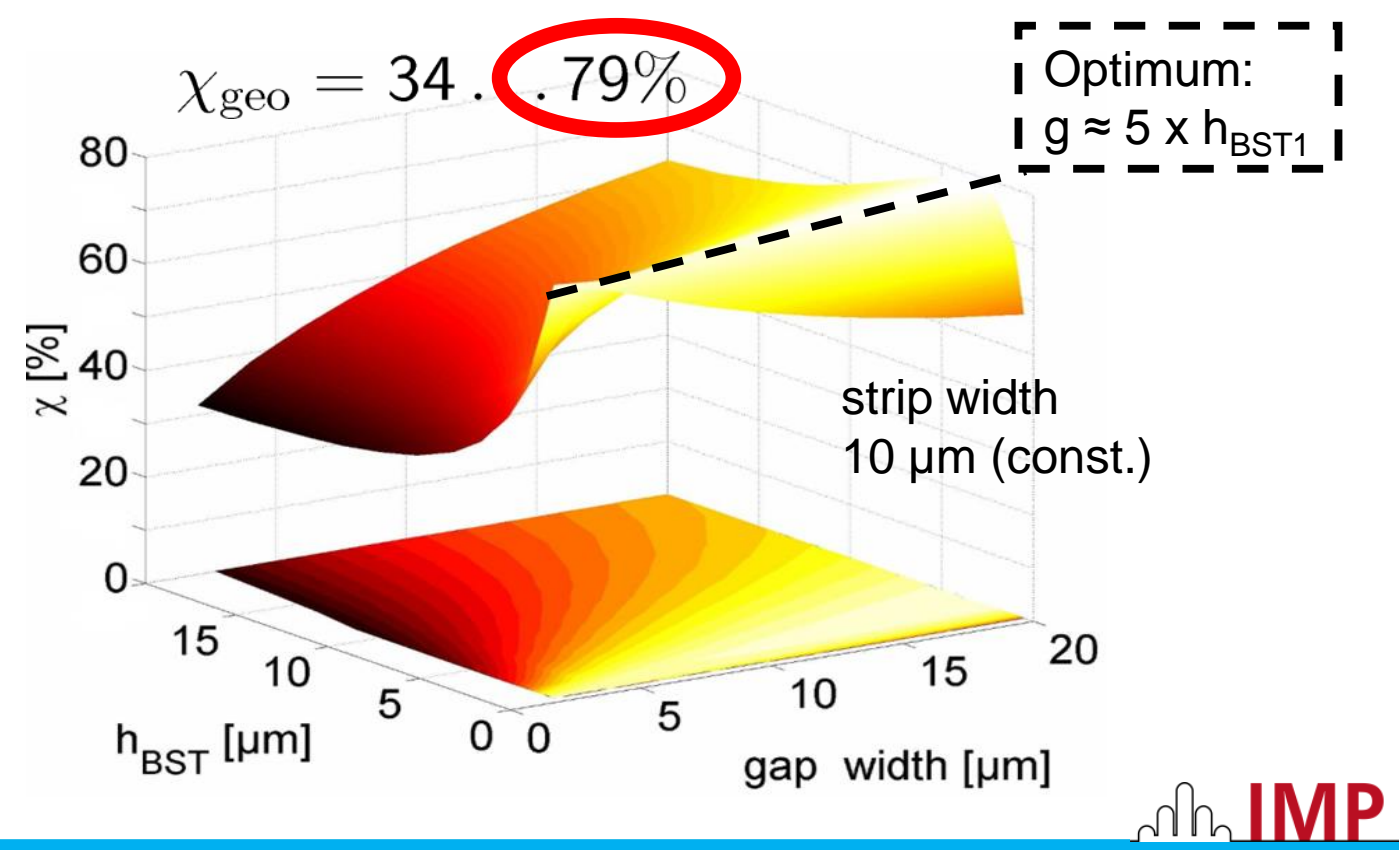




\section{MIM Varactor}

- Metal Isolator Metal Capacitors (MIM):

$\checkmark$ Reduce biasing voltage

$\checkmark$ Increase breaking voltage

$\checkmark$ Increase maximum tunablity

$\checkmark$ Improver Insertion Loss

$\checkmark$ Decrease number of tunable units

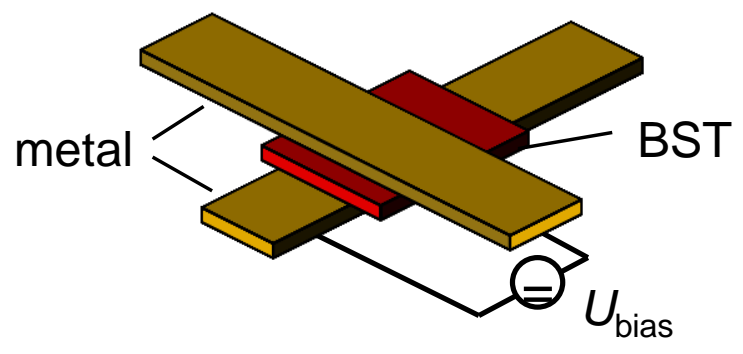

- MIM Varactor Layers:

> MIM Varactor fabricated by selective printed BST and Silver film

$>$ The bottom and top layers are metallic electrodes

$>$ The middle layer is the BST thick-film

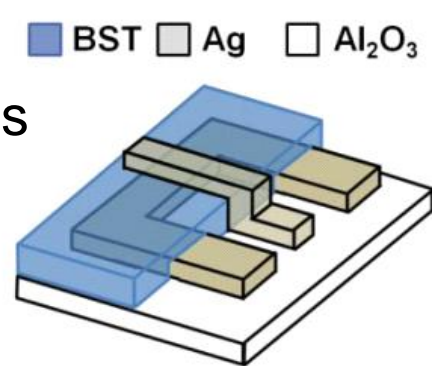

Layout of the MIM varactor

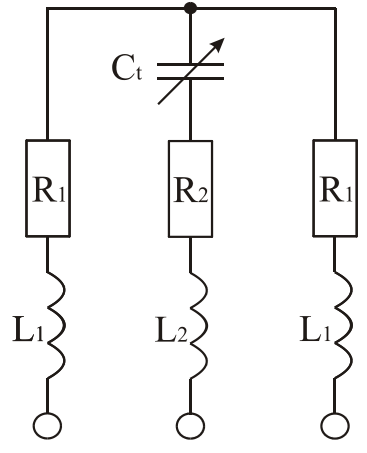

Equivalent circuit of the MIM varactor

Nhth IMP 


\section{Screen Printing}

- Printing Process:

$>$ Fast

$>$ Cost effective

$>$ Low fabrication tolerances

- Degradation of the platinum layers

$>$ The increase in the number of defects in the platinum layer $(200 \mathrm{~nm})$ on top of $\mathrm{Al} 2 \mathrm{O} 3$ substrates (sintered $1 \mathrm{~h}$ ) at different sintering temperatures.

$1100^{\circ} \mathrm{C}$

$1200^{\circ} \mathrm{C}$

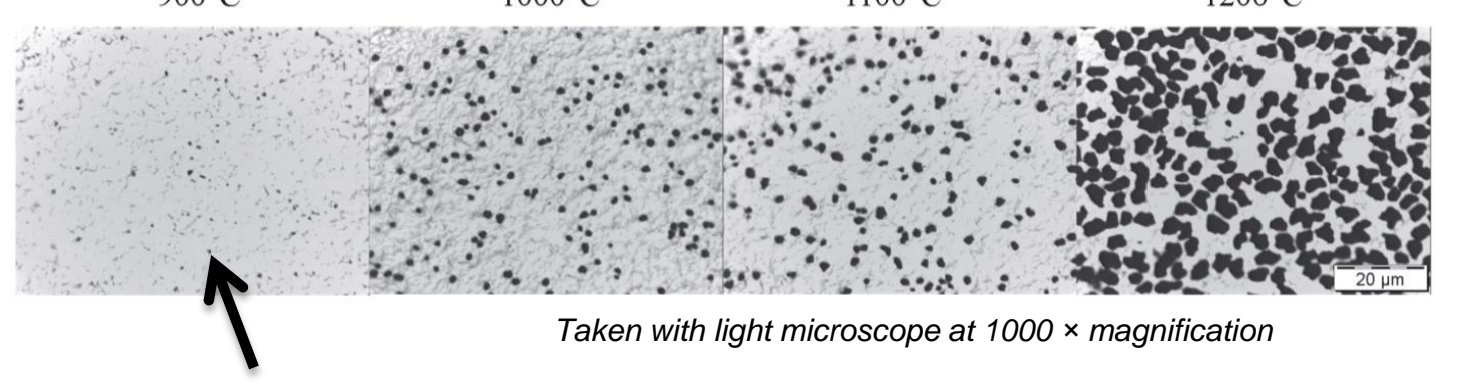

- Goal:

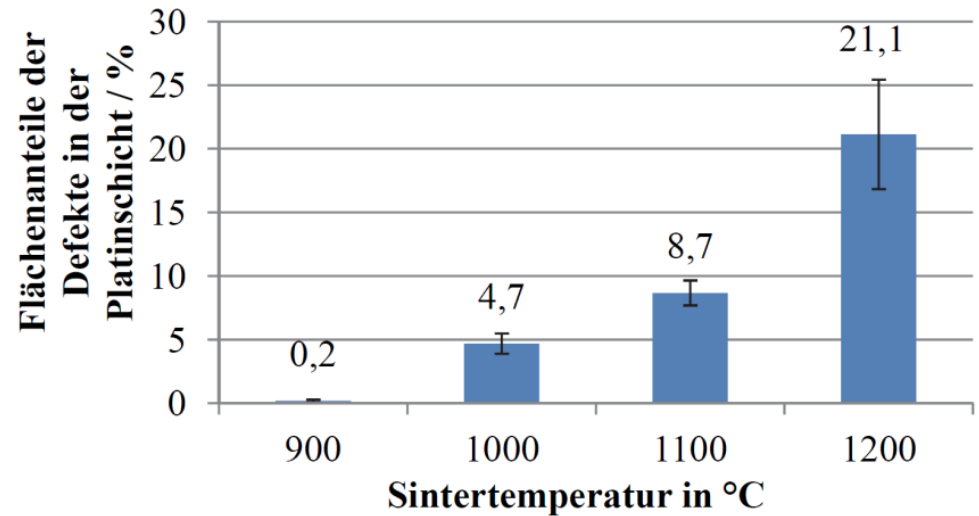

Reducing BST sintering temperature below $900^{\circ} \mathrm{C}$

Nhth IMP 


\section{Screen Printing}

$>$ The Screen printing technology:

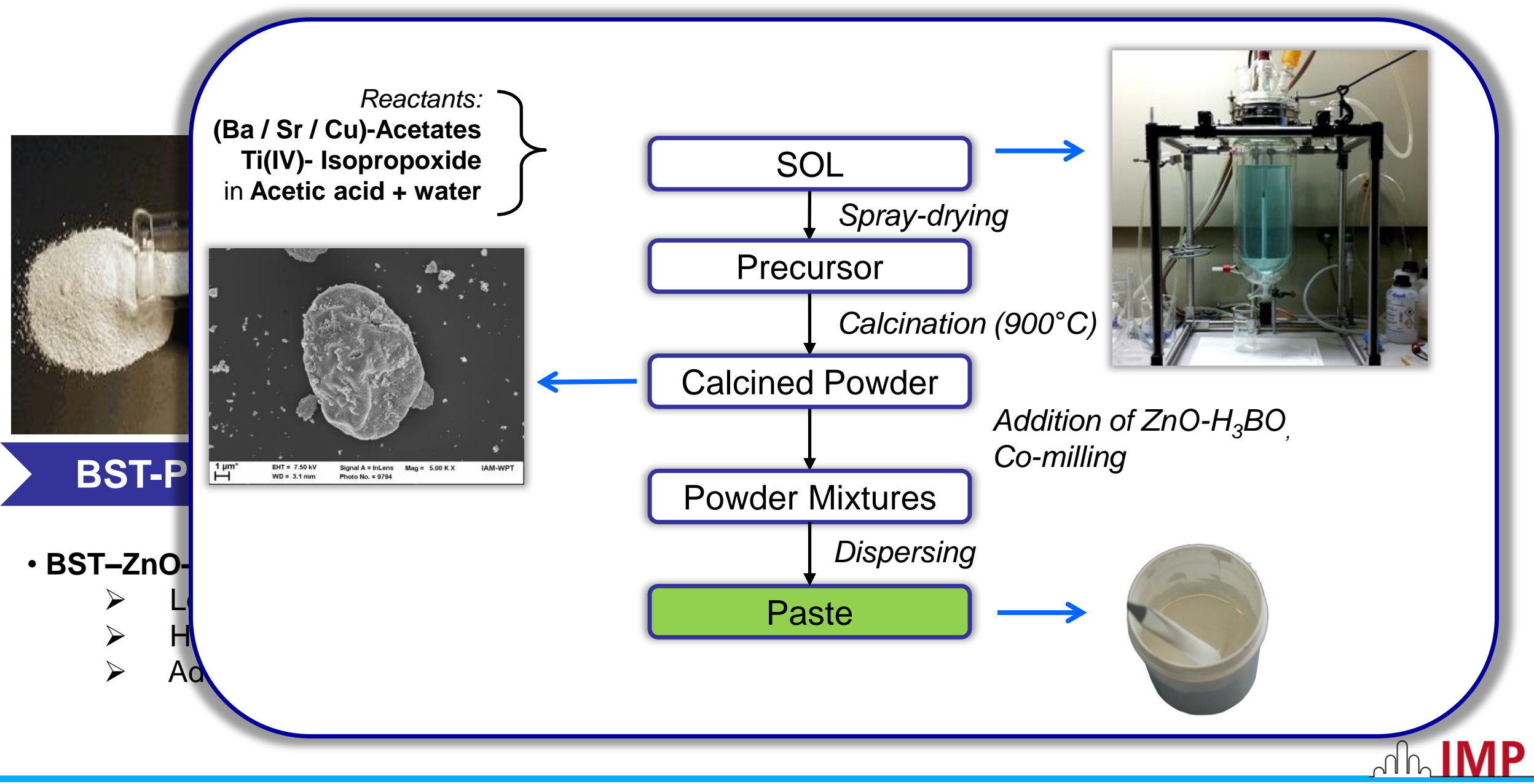




\section{Screen Printing}

TECHNISCHE UNIVERSITATT DARMSTADT

$>$ The Screen printing technology:

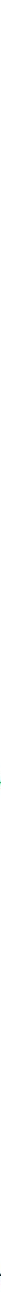




\section{MIM Varactor}

\section{- MIM Varactor Protoype:}

> The fabrication is done by subsequent screen-printing and drying of each layer

$>$ Samples were co-fired in purified dried air at a temperature of $850^{\circ} \mathrm{C}$ for $1 \mathrm{~h}$

> Measurement results of the fully printed MIM varactor over the tuning voltage at $1.7 \mathrm{GHz}$

D By applying a maximum voltage of $160 \mathrm{~V}$, a tunability of $50 \%$ is achieved

$>$ Relative permittivity $=210$ and capacitance of $3.8 \mathrm{pF}$
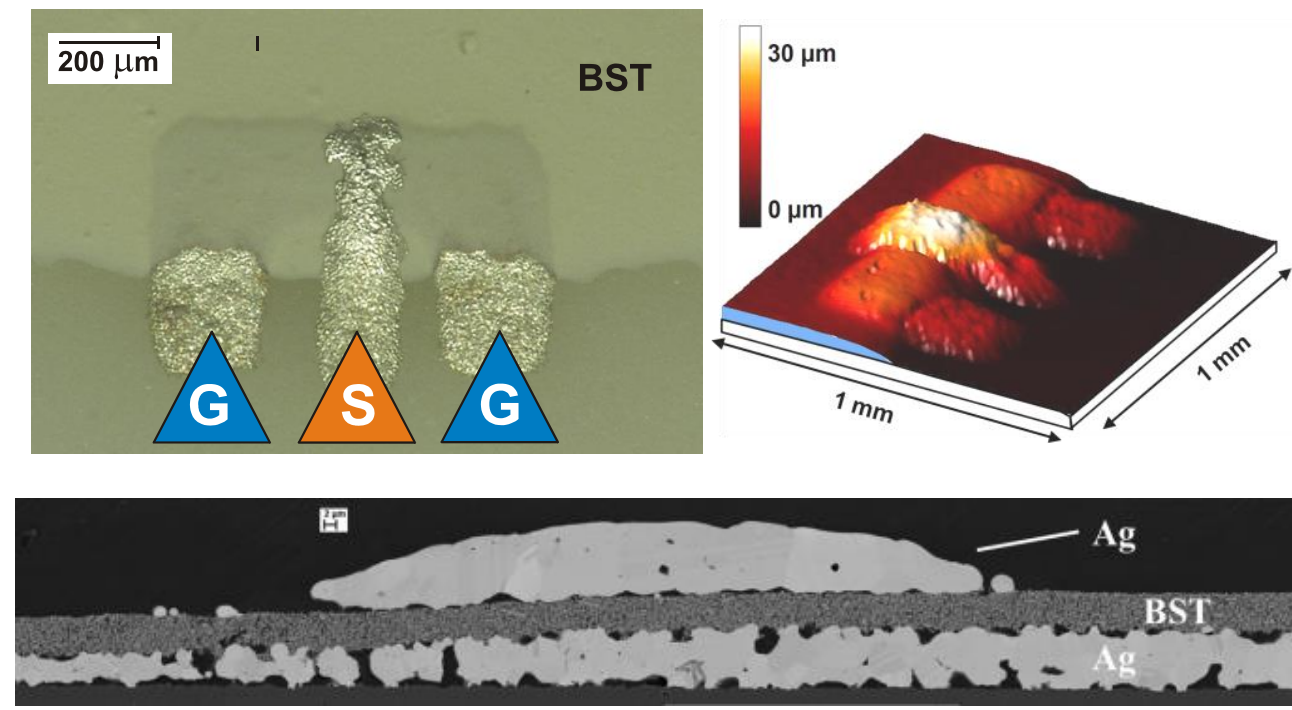

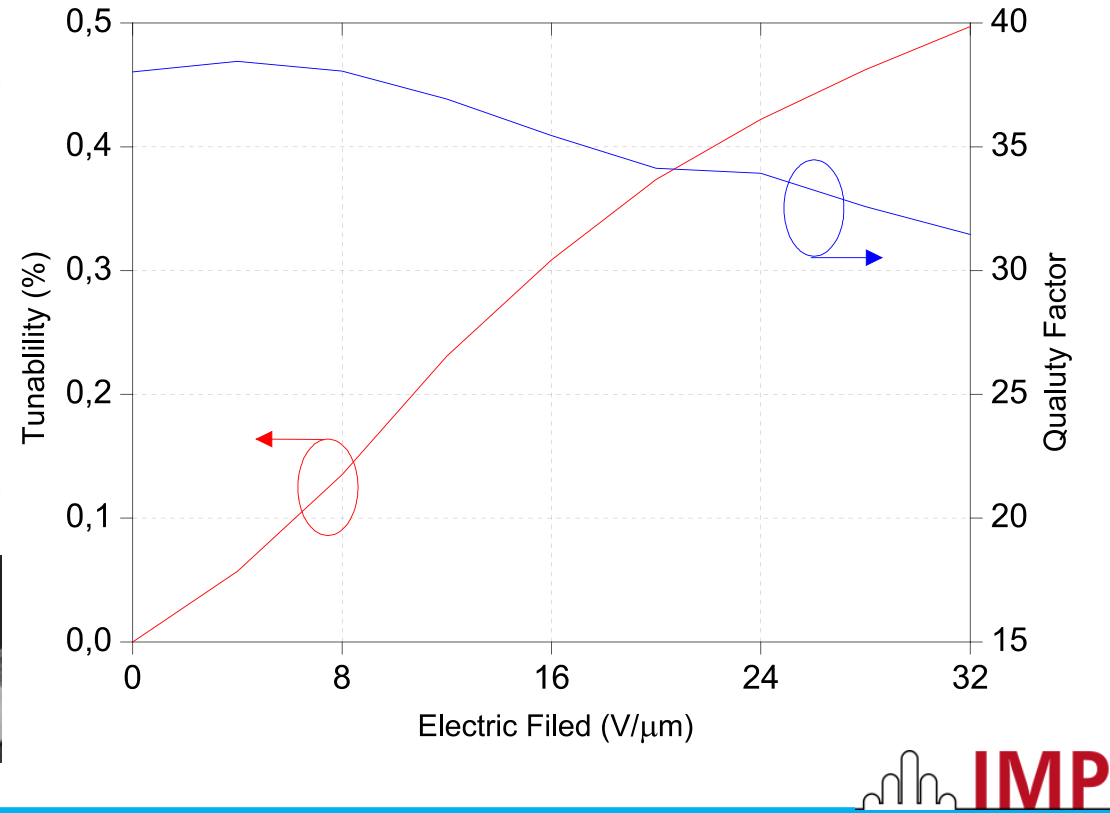




\section{Phase Shifter}

- Comparison between loaded transmission line and metamaterial delay line phase shifters

Loaded transmission line phase shifter (LL)

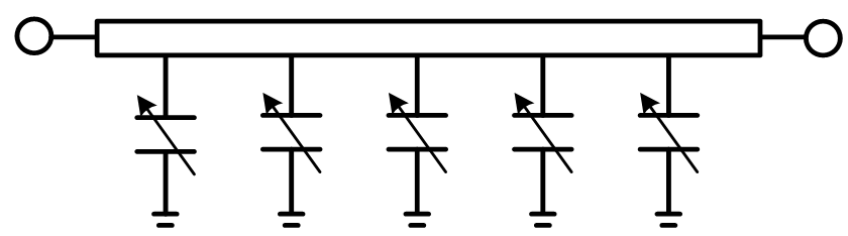

It is a broadband transmission line with shunted varactor loadings. Its positive propagation constant is controlled by tuning varactors.
Metamaterial delay line phase shifter (MM-DL)

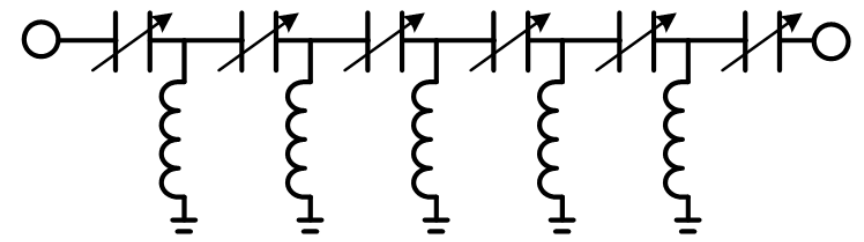

It is a chain of cascaded band pass unit cells. It can achieve equivalently zero or negative propagation constant. Ferroelectric varactors are serial connected in the line.

$$
\beta_{R H}=-\frac{1}{\omega \sqrt{L \times C_{t}}} \quad Z_{R H}=\sqrt{\frac{L}{C_{t}}}
$$




\section{Simulation}

- The unit cell equivalent circuit and layout of the loaded line phase shifter

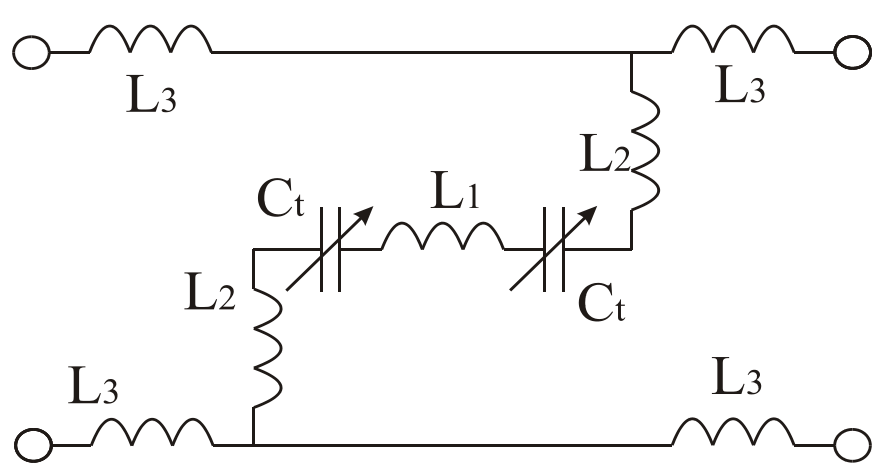

Silver Bottom Layer

Silver Bellow BST

BST layer

Silver Top Layer

Nith IMP 


\section{Phase Shifter Prototype}

\section{- Tunable phase shifter prototype:}

Center frequency at $1.7 \mathrm{GHz}$

$>$ Simulation software ADS

$>$ BST line thickness $5.9 \mu \mathrm{m}$

$>$ The intersection of the top and bottom layer of each MIM varactor is $160 \times 100 \mu m^{2}$

$>$ Conductor layer thickness $13 \mu \mathrm{m}$

$>$ Number of unit cells 7 unit cells

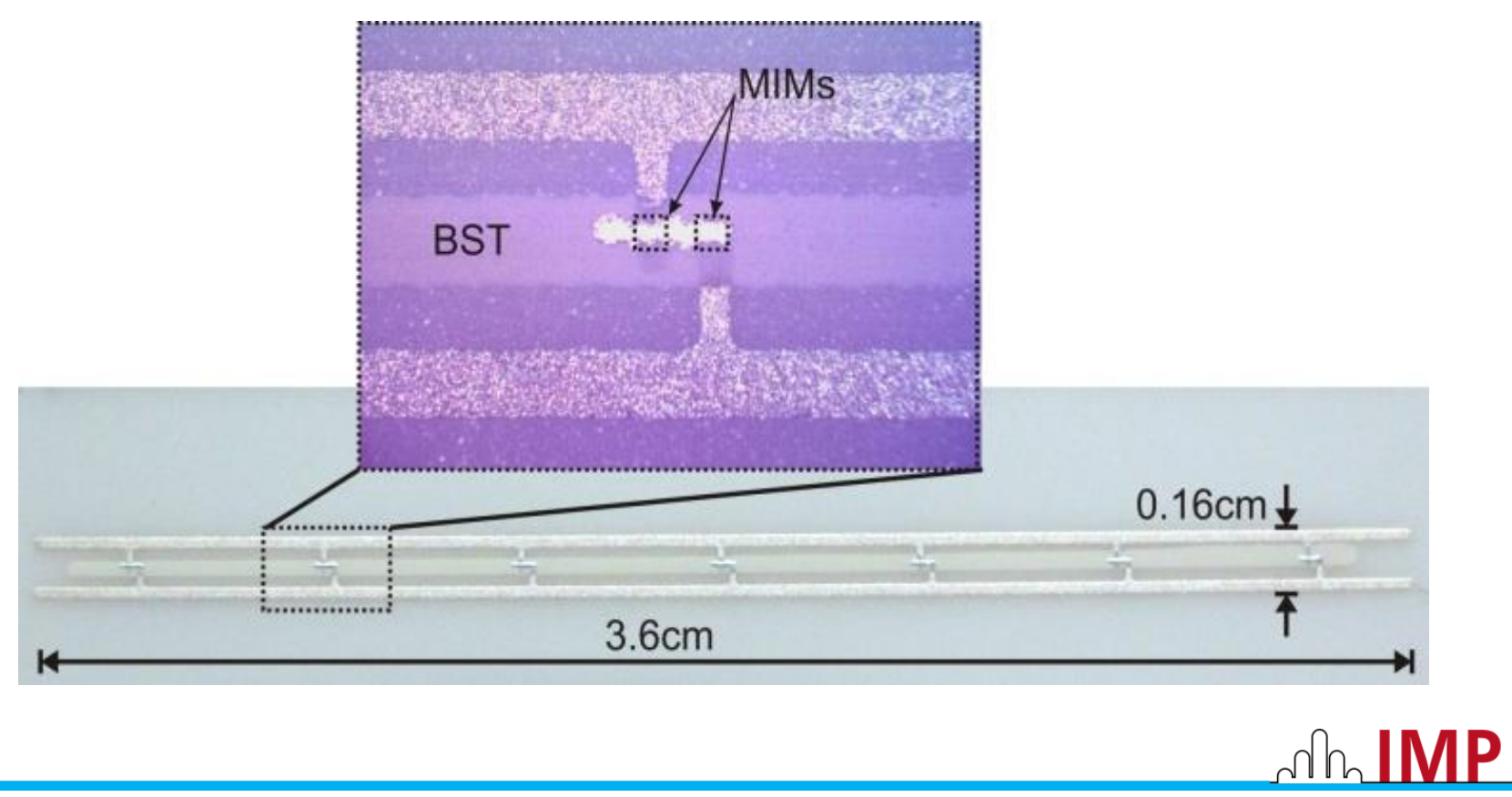




\section{Phase Shifter Prototype}

- On-Wafer measurement :

$>$ Measurement in a $50 \Omega$ system

$>$ Tuning voltage applied by using Bias-T

$>$ Tuning Voltage changed between 0 to $200 \mathrm{~V}$

$>$ Simple biasing concept

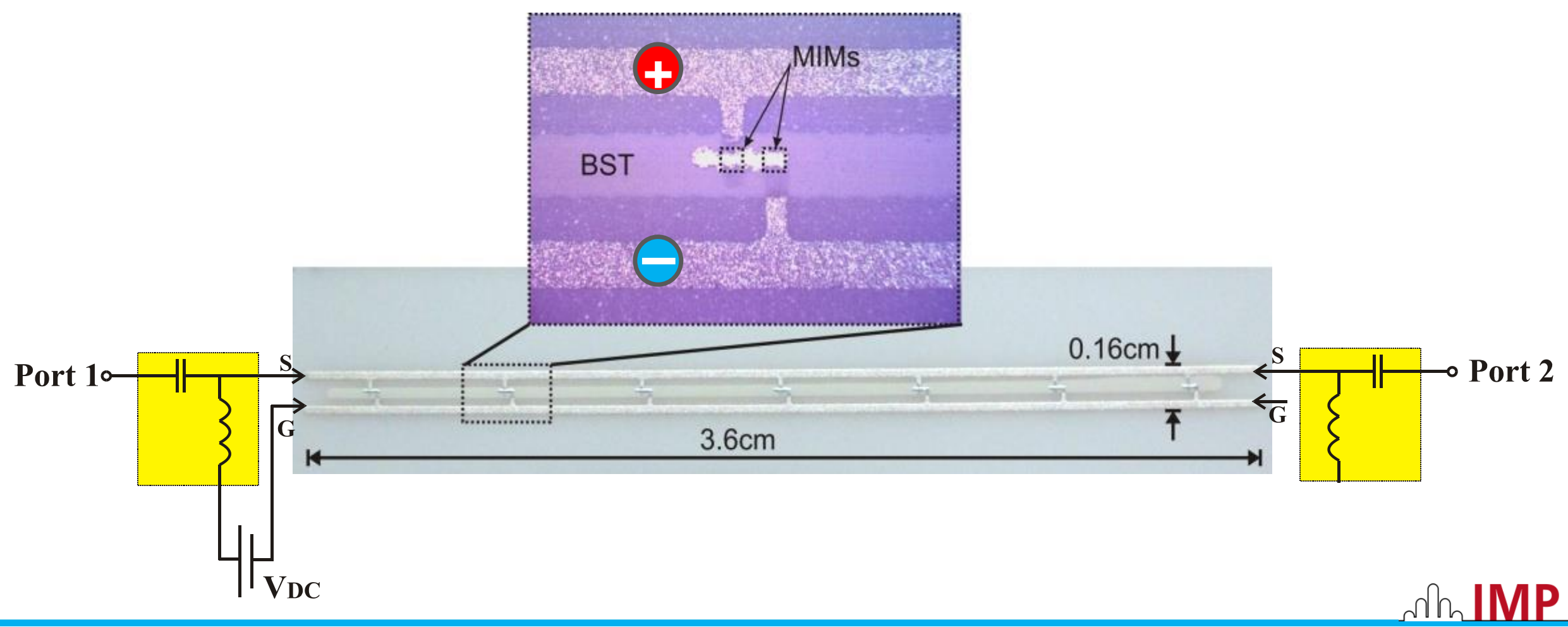




\section{Measurement results}

- S-Parameter Measurement Results:
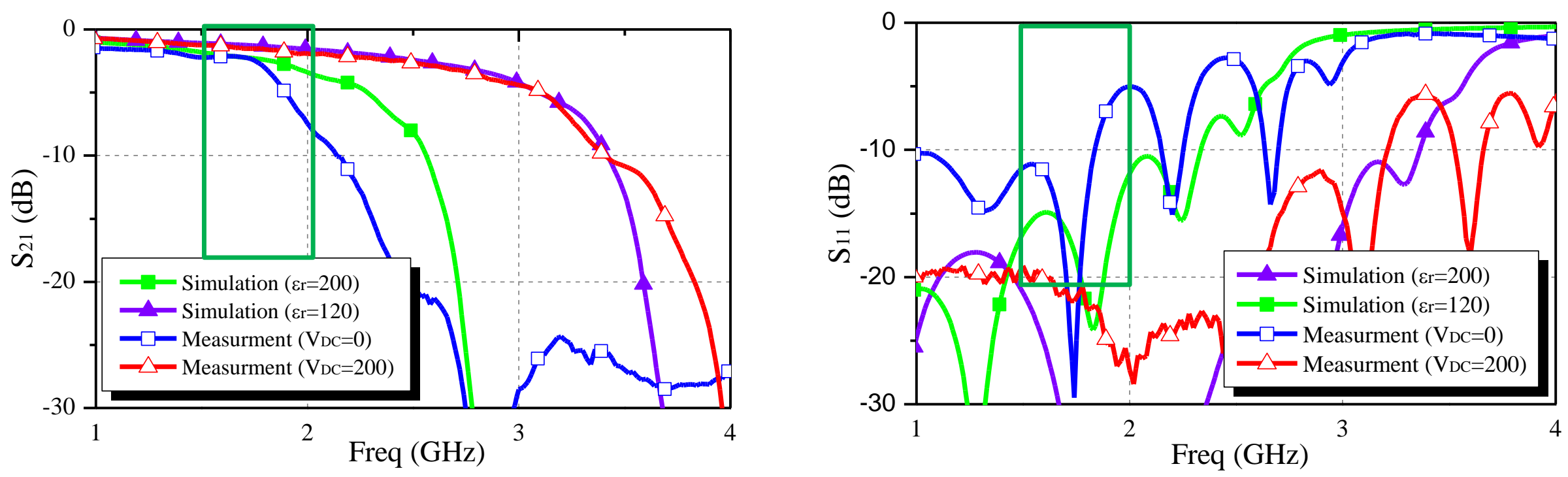

- Simulation and measurement comparison:

$>$ The fabrication tolerance

$>$ Parasitic microstrip propagation mode

$>$ The alignment accuracy 


\section{Measurement results}

- Phase Shift and Figure of merit (FoM):

$>$ A phase shift of $158^{\circ}$ is achieved at $1.72 \mathrm{GHz}$ with a FoM of $70^{\circ} / \mathrm{dB}$

$$
F o M=\frac{\Delta \varphi}{I L_{\max }}\left({ }^{\circ} / d B\right)
$$

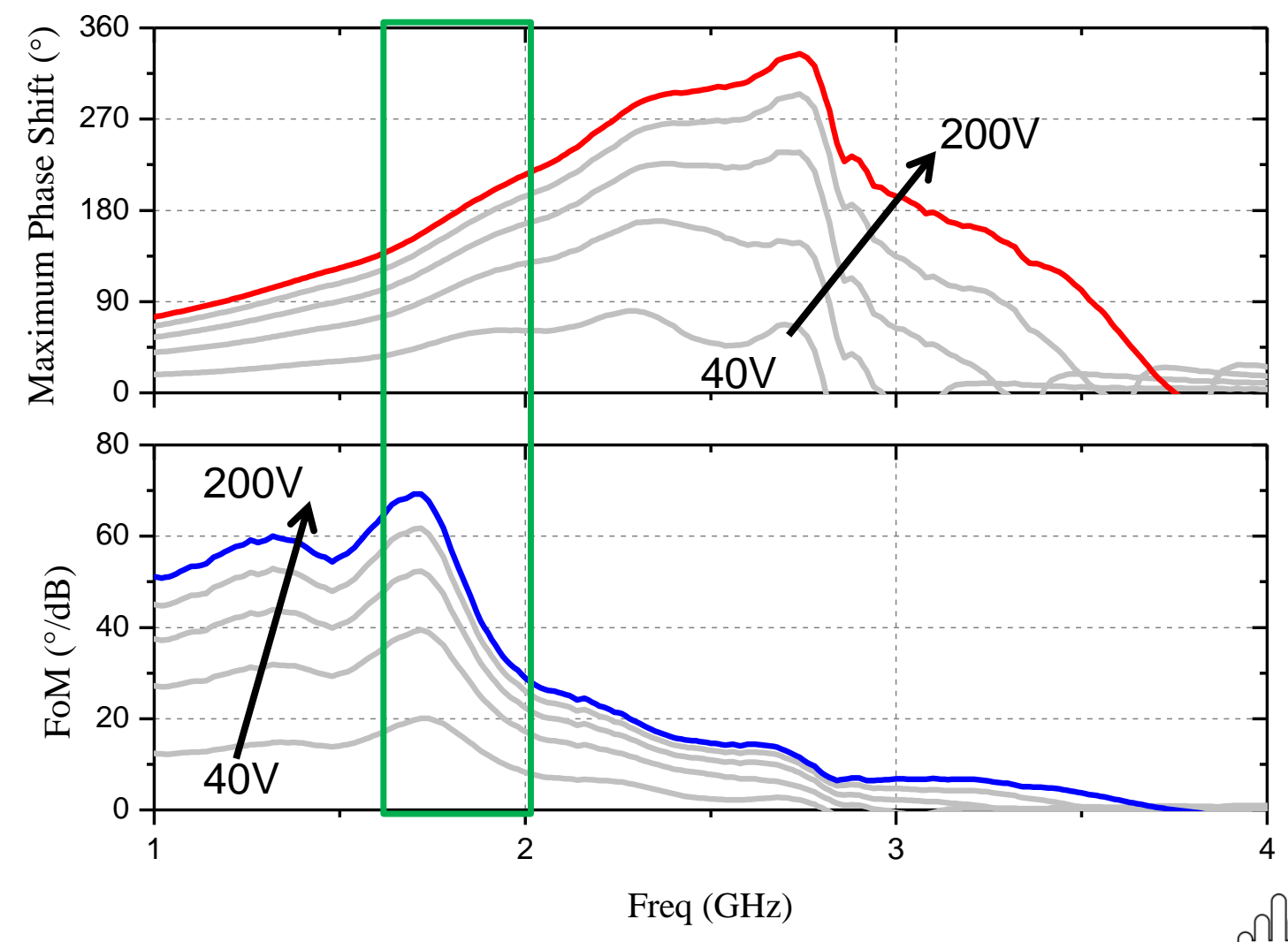




\section{Summary}

\section{- Conclusion}

$>$ The Fully screen printed technology is implemented as simple, fast and low-cost process

> Fully printed MIM varactor gives a maximum tunability of $50 \%$ by applying $160 \mathrm{~V}$

$>$ A fully screen-printed load line phase shifter is fabricated and measured at L-band

$>$ A phase shift of $158^{\circ}$ is achieved at $1.72 \mathrm{GHz}$ with a FoM of $70^{\circ} / \mathrm{dB}$

\begin{tabular}{|c|c|c|c|c|c|c|}
\hline Freq $(\mathbf{G H z})$ & $\Delta \varphi\left({ }^{\circ}\right)$ & FoM $\left({ }^{\circ} / \mathbf{d B}\right)$ & Vmax $(\mathbf{V})$ & Varactor & Sintering Temp & Ref \\
\hline 3 & 20 & 14.6 & 200 & MIM $^{*}$ & 850 & {$[4]$} \\
\hline 2.5 & 4.5 & 6.55 & 250 & MIM $^{*}$ & 850 & {$[5]$} \\
\hline 2 & 70 & 58 & 100 & MIM/IDC & - & {$[6]$} \\
\hline 2.5 & 48 & 20 & 100 & Planar & - & {$[13]$} \\
\hline 2.5 & 63 & 21 & 100 & MIM $*$ & 1200 & {$[6]$} \\
\hline 2.8 & 65 & 29 & 100 & IDC & - & {$[14]$} \\
\hline 1.75 & 158 & 70 & 200 & MIM $^{*}$ & 850 & This Work \\
\hline
\end{tabular}




\section{Summary}

\section{- Outlook}

$>$ The fabricated MIM capacitor demonstrates a simple and flexible preparation

$>$ For phased array applications, it is necessary to have $360^{\circ}$ phase shift (16 unit cells)

$>$ Higher operation frequencies are targeted, which can be reached by higher printing accuracy and reduced line width
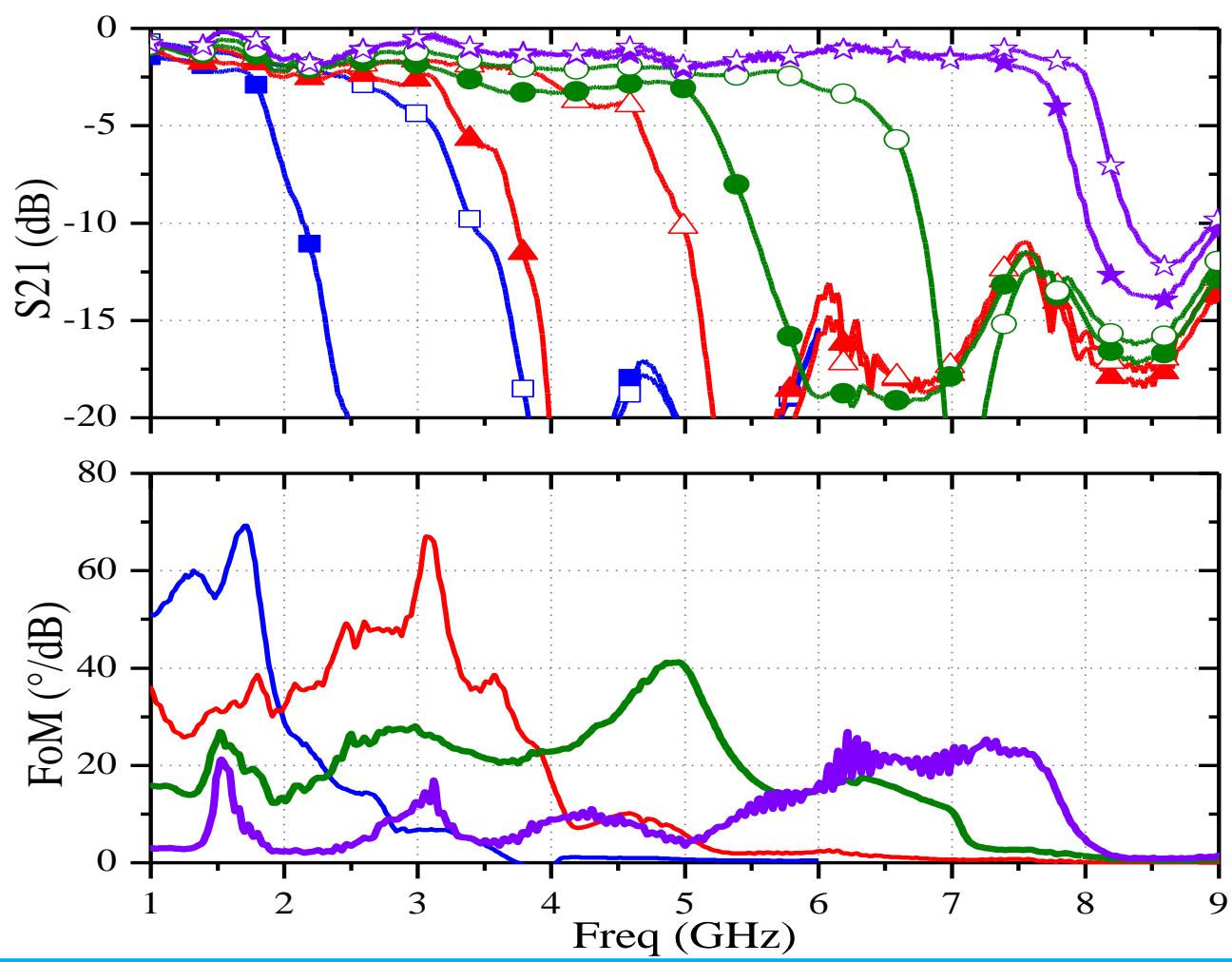
Thank you for your attention

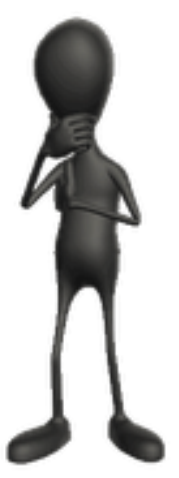

\section{Cooperation Partners}

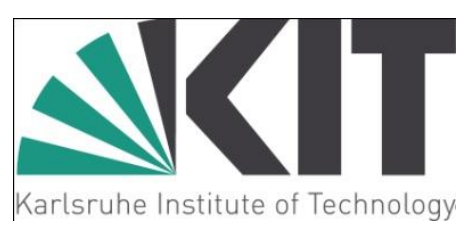

sth IMP 